\title{
Timing of Case-Based Discussions and Educational Outcomes for Dental Students
}

\author{
Jaime A. Chowaniec, Alison F. Doubleday, Charles W. LeHew, Larry B. Salzmann, \\ Anne Koerber
}

Abstract: The aim of this study was to determine if the timing of a case-based discussion affected dental students' assessment scores. The study specifically investigated whether the timing of a 60-minute case-based discussion before or after a 90-minute lecture affected students' performance on a quiz on topics in pediatric dentistry. In addition, students' preferences for the timing of the case discussion and confidence in the material with different timings were assessed in a survey. In a crossover design, all 52 second-year students in fall 2016 at one U.S. dental school participated in a case-based discussion either before or after lectures on stainless steel crowns and pulp therapy, compared to a control unit on space maintenance with no case-based discussion. The students took quizzes and responded to questionnaires a week after the lectures. A total of 45 (87\%) of the 52 students consented to have their scores used. The results showed that the students performed better on the quiz when participating in a case-based discussion after the lecture compared to the discussion before the lecture (after mean $=6.1 \pm 0.8$ vs. before mean $=5.5 \pm 1.3$ ). The students' control quiz mean following a lecture with no associated case discussion was $6.3 \pm 0.8$. Students also expressed more confidence when the case was held after the lecture $(12.7$ vs. $11.6, p=0.02)$ and preferred the case after $(\mathrm{p}=0.01)$. This study found that higher quiz and confidence scores resulted when a case discussion was held after (vs. before) a lecture. When dental educators consider adding a case discussion to a lecture format as a method of increasing students' active learning, these results suggest that having the case discussion after the lecture may be more effective for learners new to the material.

Jaime A. Chowaniec, DMD, MS, is a pediatric dentist in private practice, Glen Ellyn and Palos Heights, IL, and was a pediatric dental resident, University of Illinois at Chicago, at the time the study was conducted; Alison F. Doubleday, PhD, MA, is Associate Professor, Department of Oral Medicine and Diagnostic Sciences, University of Illinois at Chicago; Charles W. LeHew, PhD, is Research Assistant Professor, Department of Pediatric Dentistry, University of Illinois at Chicago; Larry B. Salzmann, DDS, is Clinical Associate Professor, Predoctoral Director of Pediatric Dentistry, and Clinic Director, Department of Orthodontics and Pediatric Dentistry, University of Michigan School of Dentistry; and Anne Koerber, DDS, PhD, is Professor and Educational Assessment Director, Department of Oral Medicine and Diagnostic Sciences, University of Illinois at Chicago. Direct correspondence to Dr. Anne Koerber, Department of Oral Medicine and Diagnostic Sciences, University of Illinois at Chicago College of Dentistry, 801 S. Paulina Street, Room 558A (MC 838), Chicago, IL 60612-7213; 312-996-9341; akoerber@uic.edu.

Keywords: dental education, educational methodology, case-based learning, pediatric dentistry

Submitted for publication 7/24/17; accepted 11/13/17

doi: 10.21815/JDE.018.056

$\mathrm{T}$ The traditional pedagogical approach to education in the health professions is a professor delivering a lecture to a large group of students, sometimes for several hours. Unfortunately, this method of teaching may not foster the critical thinking skills essential to creating a competent dentist. The average student's attention span is much less than the length of the average dental school lecture, and students frequently have lapses in attention during a passive didactic session. ${ }^{1}$ With an active approach to learning, students may become more engaged and glean a greater understanding of the information compared to those in a passive lecture environment. $^{2}$ The 1995 Institute of Medicine report and Hendricson et al. recommended a shift to active learning strategies and specifically recommended using case discussions for this purpose. ${ }^{3,4}$

Case-based learning (CBL) is a viable approach to help initiate the shift to more active learning and encourage critical thinking. ${ }^{5,6} \mathrm{CBL}$ employs clinical cases, typically for the duration of one class session, to enhance foundational knowledge or highlight a particular topic..$^{7-9}$ Case-based discussions have been used to promote reflection and clinical reasoning and to combat the challenges of limited patient populations for student exposure to specific cases. ${ }^{10}$ CBL may depend upon preparation outside a class discussion session, and each case is typically focused on one particular topic. ${ }^{11}$ Although Samuelson et al. found improvements in assessment scores with exposure to $\mathrm{CBL},{ }^{12}$ other studies have not found such improvement: rather, increased student confidence, improved communication skills, student satisfaction, and enjoyment of the activity, as well as increased interaction among students, have been reported as benefits of the method. ${ }^{12-16}$ A systematic review of the literature on CBL in health professions education reported in 2012 that the data addressing 
the effects of CBL on learning were inconclusive regarding improvements in learning. ${ }^{16}$ That review noted that the data did, however, provide evidence for increased enjoyment by instructors and students, increased motivation for learning, and a belief in the effectiveness of the method for learning associated with the use of CBL.

The aim of this study was to determine if the timing of a case-based discussion affected dental students' assessment scores. A case-based discussion before a lecture could introduce material to be further discussed in a later lecture in order to stimulate thinking about the topic and to prime students to be more engaged during the lecture. On the other hand, a case discussion after a lecture could reinforce concepts from the lecture and better allow students to process information. Although there is considerable literature addressing the use of CBL in health professions curricula, we could not identify any published studies investigating the specific timing of case-based discussions in relation to lectures in the context of dental education. This study thus compared the outcomes of a case-based discussion before and after a lecture to add to the understanding of how active learning modalities can contribute to students' learning. Specifically, we assessed the potential benefits of adding a case-based discussion to supplement a traditional lecture and compared the effect of timing of the case-based discussion relative to the accompanying lecture.

\section{Methods}

All methods used in this study were approved as exempt by the Institutional Review Board of the University of Illinois at Chicago (protocol \#20160317). To investigate the timing of case-based discussions, a case-based strategy was implemented in a course in pediatric dentistry. This course taught in the second year introduces dental students to the basic concepts of pediatric dentistry. Before the study, this course consisted of 90-minute lectures with laboratory exercises. With this study, a case discussion was added to the format for two units, and a third unit consisting of lecture-only was examined for comparison. The units chosen for the study were stainless steel crowns, pulp therapy, and space maintenance. The course director (LS) chose these units because students struggle with these topics and because this material was wholly new to students at this level.
All 52 second-year students enrolled in the course in fall 2016 were invited to participate in the study. To investigate the effect of the timing of case discussions, a randomized cross-over design was used (Figure 1). We also examined a third unit with no case discussion to ensure that the two randomized groups were similar. The students who agreed to participate were divided randomly into two groups (A and B) using Microsoft Excel's randomization function (Microsoft, Redmond, WA, USA). Since it was important that the two groups comprised similar proportions of study subjects and non-study subjects, the students who did not consent to participate (nonsubjects) were also randomly distributed into the two groups.

Group A first participated in a 60-minute casebased discussion session on stainless steel crowns. A lecture was presented later on the same day. Still later that day, Group B participated in the case discussion using the same case with the same facilitator. The following week, Group B participated in the case discussion for pulp therapy prior to the lecture, while Group A participated in the case discussion following the lecture on the same day. On the third week, the lecture was provided on space maintainers and with no case discussion.

During the case discussions, students worked through a five-page case, one page at a time, with the facilitator moderating the discussion. Students were permitted to reference textbooks, the Internet, or class notes during the discussions. At the end of each case,

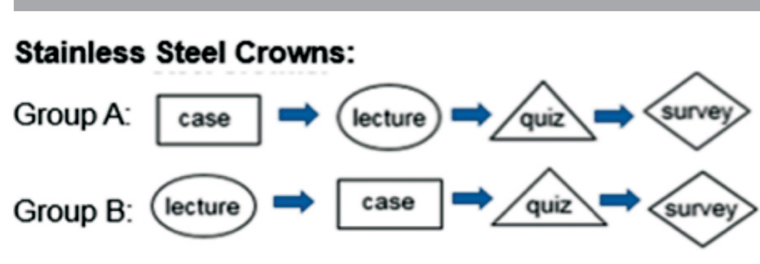

Pulp Therapy:

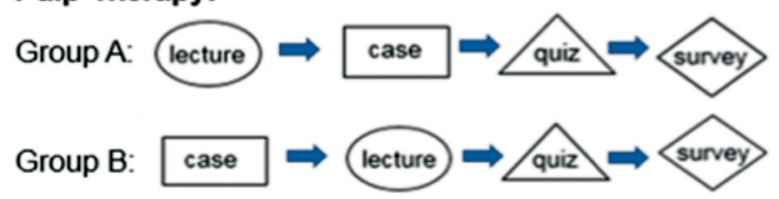

Space Maintenance:

Group A and B:

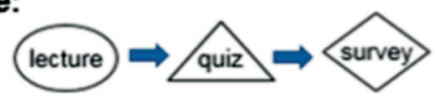

Figure 1. Crossover design of study comparing outcomes in three units with a case discussion before and after a lecture with lecture-only 
students were given a set of session learning objectives, and they reviewed whether the objectives had been achieved during the session.

The case for the stainless steel crown unit was of a four-year-old child presenting for a recall exam, with a history of restorative treatment and a new large carious lesion on a mandibular primary molar. Students identified the issues involved in caries risk assessment and then walked through the process of providing a stainless steel crown, including armamentarium and local anesthetic. The case for the pulp therapy unit was of a seven-year-old child presenting with a toothache in an upper primary first molar. The students discussed how to make the decision regarding pulp treatment, the explanation to the mother and child of the proposed treatment, and the armamentarium and steps of the procedure, including local anesthetic. The assessment questions were all answerable from the material covered in the case discussions.

The principal investigator (JAC), who was also a teaching assistant and resident in pediatric dentistry, facilitated all the discussions. She had prior experience in problem-based learning facilitation for which she had completed a week-long training program. She designed the cases with the course director to support the lecture material.

The learning outcome was assessed with a quiz administered one week after the session, consisting of seven true/false and multiple-choice questions. The course director wrote all questions, which were taken from his question bank developed over the years. The quizzes were used as feedback to help the students and instructors assess how well the student grasped the material. The quiz scores were not used in the calculations of final grades.

Student confidence was evaluated with a questionnaire, also administered one week after the session, using a five-point Likert scale on which students reported their agreement with confidence level in each of the following: overall knowledge, treatment planning abilities, clinical knowledge, and didactic knowledge of the three content areas. Students' preference for the timing of the case discussion was administered on the last day of class. The survey and confidence data were not linked to the student scores.

After the grading was complete, the data of the students who refused permission were removed from the data set, and the data were de-identified. Frequently, students responded to the confidence and preference questionnaires even when they had refused permission to use their assessment scores, so these data included information from some non- participating students as well. The data from the questionnaires were not linked to the assessment scores.

All data were analyzed using SPSS for Windows, Version 22.0 (IBM Corp., Armonk, NY, USA). To determine if the two groups were equivalent, a t-test compared learning outcomes for the condition of no discussion. The learning outcomes were next compared using a two-way, repeated measures ANOVA to compare the before and after conditions. To better understand the variance in learning outcomes, they were also compared by unit using ANOVA. Confidence ratings were compared using one-way ANOVAs with Dunnet's t post hoc tests. Student preference for the timing of the case discussion was analyzed using chi square analysis.

\section{Results}

Forty-five (87\%) of the 52 students consented to having their grades in pediatric dentistry used in the study. After randomized assignment to two groups, the groups performed equally on the unit without case discussion ( $\mathrm{t}=0.9,40 \mathrm{df}, \mathrm{p}=0.8$, with the means of Group $\mathrm{A}=6.3 \pm 0.8$ and Group $\mathrm{B}=6.2 \pm 0.8$ ), demonstrating the groups were equivalent.

Table 1 shows the mean scores for the assessments for the three units, compared both by timing of the case discussion and by unit. The scores were higher when the case discussion occurred after the lecture compared to before the lecture $(\mathrm{p}=0.008)$. However, the after scores did not differ from the no discussion condition. Scores on the pulp therapy unit were lower than on the other two units ( $p=0.028$ and $\mathrm{p}=0.002$ ).

The results of the student confidence ratings are shown in Table 2. The responses from the confidence questions were summed, with the highest possible confidence score as 20 . The students who had the case discussion after the lecture rated their confidence higher than those who had the case discussion before the lecture $(p=0.046)$, but not higher than the no discussion condition $(\mathrm{p}=0.055)$. The unit on space maintainers was rated with more confidence than either the unit on stainless steel crowns or the unit on pulp therapy $(\mathrm{p}=0.014$ and $\mathrm{p}<0.001)$.

Of the 52 students, 47 responded to a questionnaire on format preferences. The students preferred the case discussion after the lecture $(\mathrm{p}=0.01)$ (Table 3 ). Although a higher proportion of students preferred a lecture with a case discussion, this was not significantly different from the proportion who preferred lecture-only or who liked both equally ( $\mathrm{p}=0.3$ ). 
Table 1. Students' scores compared by timing of case discussion, unit content, and group

\begin{tabular}{|c|c|c|c|}
\hline Unit/Timing† & $\begin{array}{c}\text { Case Before Lecture } \neq \\
\text { Mean (SD) }\end{array}$ & $\begin{array}{c}\text { Case After Lecture } \\
\text { Mean (SD) }\end{array}$ & $\begin{array}{l}\text { Total by Unit } \\
\text { Mean (SD) }\end{array}$ \\
\hline Unit 1 stainless steel crowns & $\begin{array}{c}5.8(1.0) \\
\mathrm{n}=22(\text { Group A) }\end{array}$ & $\begin{array}{c}6.2(1.1) \\
\mathrm{n}=21(\text { Group B) }\end{array}$ & $\begin{array}{l}6.0(1.0) \mathrm{n}=43 \\
\text { Range } 3-7\end{array}$ \\
\hline Unit 2 pulp therapy & $\begin{array}{c}5.2(1.5) \\
n=21(\text { Group B) }\end{array}$ & $\begin{array}{c}5.9(1.0) \\
\mathrm{n}=23(\text { Group A) }\end{array}$ & $\begin{array}{l}5.5(1.3) \mathrm{n}=44 \\
\quad \text { Range } 2-7\end{array}$ \\
\hline Unit 3 space maintainers & & & $\begin{array}{c}6.3(0.8) \mathrm{n}=42 \\
\text { Range } 4-7\end{array}$ \\
\hline Total by timing of case & $\begin{array}{c}5.5(1.3) \\
n=43\end{array}$ & $\begin{array}{c}6.0(1.0) \\
n=44\end{array}$ & \\
\hline
\end{tabular}

Note: Seven points were possible for each quiz.

tOn these four measures, repeated measures ANOVA with planned contrasts: Unit $1>$ Unit 2: $F=5.2,1 \mathrm{df}, \mathrm{p}=0.028$; Unit $3>$ Unit 2: $\mathrm{F}=1.6,1 \mathrm{df}, \mathrm{p}=0.002$; and no difference between Unit 1 and Unit 3: $\mathrm{F}=1.6,1 \mathrm{df}, \mathrm{p}=0.21$.

¥Scores with case discussion before lecture were significantly lower than the other two modalities (case discussion after lecture and no case discussion), using repeated measures ANOVA with planned contrasts: $F=8.27,2$ \& $78 \mathrm{df}, \mathrm{p}=0.008$.

Table 2. Students' confidence scores by timing of case discussion and content of unit

\begin{tabular}{lccc} 
Unit/Total & $\begin{array}{c}\text { Case Before Lecture } \\
\text { Mean (SD) }\end{array}$ & $\begin{array}{c}\text { Case After Lecture } \\
\text { Mean (SD) }\end{array}$ & $\begin{array}{c}\text { Total by Unitt } \\
\text { Mean (SD) }\end{array}$ \\
\hline Unit 1 stainless steel crowns $\mathrm{n}=50$ & $11.8(2.1)$ & $13.1(2.3)$ & $12.5(2.4)$ \\
Unit 2 pulp therapy $\mathrm{n}=48$ & $11.4(1.9)$ & $12.3(2.3)$ & $11.7(2.2)$ \\
Unit 3 space maintainers $\mathrm{n}=48$ & $11.6(2.0)$ & $12.7(2.3)$ & $14.0(2.8)$ \\
Total by timing of case & $11.8)$
\end{tabular}

Note: Confidence scores could have a high of 20 points; actual scores ranged from 7 to 19 .

tANOVA comparing by unit, $\mathrm{F}=10.7,2 \& 143 \mathrm{df}, \mathrm{p}<0.001$. Dunnet's $T$ post hoc tests: unit $3>$ unit $1, \mathrm{p}=0.014 ;$ unit $3>$ unit 2 , $\mathrm{p}<0.001$; no difference between unit 1 and unit $2, \mathrm{p}=0.3$.

¥ANOVA comparing before, after, and space maintainers, $\mathrm{F}=12.02,2$ \& $135 \mathrm{df}, \mathrm{p}<0.001$. Dunnet's T post hoc tests: after $>$ before $\mathrm{p}=0.046$, space maintainers $>$ before, $\mathrm{p}<0.001$, and not different from after $\mathrm{p}=0.055$.

Table 3. Students' preferences for timing of case-based discussion and modality $(\mathrm{N}=47)$

\begin{tabular}{lcc} 
Preference & Expected N & Observed N \\
\hline Timing & & \\
$\quad$ Case before lecture & 23.5 & 14 \\
Case after lecture & 23.5 & 33 \\
$\begin{array}{l}\text { Modality preference } \\
\text { Lecture with case }\end{array}$ & 15.7 & \\
Lecture only & 15.7 & 13 \\
Liked both equally & 15.7 & 13
\end{tabular}

Note: For timing, $\mathrm{c}^{2}=7.68,1 \mathrm{df}, \mathrm{p}=0.01$; for modality preference, $c^{2}=2.72,2 d f, p=0.26$.

\section{Discussion}

In dental education, case-based discussions are often used as an active learning strategy for students. This study found an increased effect of case discussions after a lecture compared to before, regarding learning outcome, student confidence, and student preference. We could find no other studies comparing the effects of the timing of a case-based discussion on dental student outcomes.

The likely explanation of our findings is that having the case after the lecture allowed the students to consolidate and apply the learning that occurred during the lecture. Intuitively, this process seems more satisfying for students than throwing them into an unknown situation and asking them to figure out the situation before the lecture. However, it is possible 
that there are educational situations in which the case presentation beforehand would be more effective. An example would be that of a flipped classroom, wherein the student was expected to read the material, was assessed on it, and then was asked to apply that material during a case discussion. Timing the lecture after the case discussion would then allow students to access an expert in order to ask more advanced questions about application and would allow the expert to demonstrate how the application of the content changes with different types of cases.

A previous study found that the advantages of a case-based discussion as part of the learning experience were student confidence and preference. ${ }^{15}$ In our study, student confidence was higher when the case discussion occurred after the lecture, and the students' preference for the timing of the case was for after the lecture, supporting the previous findings.

A limitation of our study was that the study design was not adequate to compare lectures with a case discussion to lectures without a case discussion since students were not randomly assigned to those conditions. It is worth noting that student performance was slightly better on the lecture with no cases. This result was consistent with those found in a systematic review. ${ }^{16}$ Another limitation is that since the lecture-only unit was the third unit presented in this study, students may have become more skilled at taking the weekly assessments by that time and therefore performed better. In addition, the content of space maintainers appears to have been easier than the content of stainless steel crowns or pulp therapy. For whatever reason, our data did not demonstrate any advantage to having a case discussion over a lecture-only session. Finally, since this study took place in only one year at one dental school, the results may not be generalizable to students at other institutions.

\section{Conclusion}

This study of the timing of a case-based discussion for second-year dental students found that the students scored higher, rated their confidence higher, and preferred having a case-based discussion after the lecture instead of before the lecture. As dental educators, we are encouraged to implement active learning activities into our curricula. Our findings suggest that if a case discussion is incorporated into the learning activities of dental students, it may be more effective and better received if it occurs after a lecture. We need to continue to find ways of evaluating the effectiveness of various learning activities, and we need to continue to ponder how findings in one school might generalize to other settings. Future studies should consider other aspects of active learning beyond brief multiple-choice assessment scores, such as essays to analyze cases. Future research could also examine how other aspects of and formats for active learning affect educational outcomes.

\section{REFERENCES}

1. Johnstone A. Attention breaks in lectures. Educ Chemistry 1976;13(2):49-50.

2. Prince M. Does active learning work? A review of the research. J Eng Educ 2004;93(3):223-31.

3. Field MJ, Jeffcoat MK. Dental education at the crossroads: a report by the Institute of Medicine. J Am Dent Assoc 1995;126(2):191-5.

4. Hendricson WD, Andrieu SC, Chadwick DG, et al. Educational strategies associated with development of problem-solving, critical thinking, and self-directed learning. J Dent Educ 2006;70(9):925-36.

5. Popil I. Promotion of critical thinking by using case studies as teaching method. Nurse Educ Today 2011;31(2):204-7.

6. Nadershahi NA, Bender DJ, Beck L, et al. An overview of case-based and problem-based learning methodologies for dental education. J Dent Educ 2013;77(10):1300-5.

7. McLean S. Case-based learning and its application in medical and health care fields: a review of worldwide literature. JMECD 2016;3:39-49.

8. Srinivasan M, Wilkes M, Stevenson F, et al. Comparing problem-based learning with case-based learning: effects of a major curricular shift at two institutions. Acad Med 2007;82(1):74-82.

9. Koole S, De Wever B, Aper L, et al. Using online periodontal case-based discussions to synchronize theoretical and clinical undergraduate dental education. Eur J Dent Educ 2012;16(1):52-8.

10. Koole S, Fine P, De Bruyn H. Using discussion groups as a strategy for postgraduate implant dentistry students to reflect. Eur J Dent Educ 2016;20(1):59-64.

11. Flynn AE, Klein JD. The influence of discussion groups in a case-based learning environment. Educ Technol Res Dev 2001;49(3):71-86.

12. Samuelson DB, Divaris K, de Kok IJ. Benefits of casebased versus traditional lecture-based instruction in a preclinical removable prosthodontics course. J Dent Educ 2017;81(4):387-94.

13. Thomas MD, O'Connor FW, Albert ML, Boutain D. Case-based teaching and learning experiences. Iss Mental Health Nurs 2001;22(5):517-31.

14. Kumar V, Gadbury-Amyot CC. A case-based and teambased learning model in oral and maxillofacial radiology. J Dent Educ 2012;76(3):330-7.

15. McKenzie CT. Dental student perceptions of case-based educational effectiveness. J Dent Educ 2013;77(6):688-94.

16. Thistlethwaite JE, Davies D, Ekeocha S, et al. The effectiveness of case-based learning in health professional education: a BEME systematic review. BEME guide no. 23. Med Teach 2012;34(6):e421-44. 